\title{
Mechanical properties of snow using indentation tests: size effects
}

\author{
Daisy HUANG, Jonah H. LEE \\ Department of Mechanical Engineering, University of Alaska Fairbanks, Fairbanks, AK, USA \\ E-mail: Jonah.lee@alaska.edu
}

\begin{abstract}
An attempt is made to obtain and quantify the mechanical properties of two common types of seasonal snow on the ground. Different samples of natural snow whose metamorphism had stabilized (such as would remain on a road throughout winter in a cold, snowy area) were gathered and tested using mesoscale indentation tests (metrics on the order of $\mathrm{mm}$ to $\mathrm{cm}$ ). Results from the stress vs displacement curves from indentation indicated that (1) first peak strength decreased, according to a power law, with increasing indenter size and was not affected by snow average grain size, (2) plateau strength decreased with increasing indenter size, and snow compaction strength might be calculated from these data, and (3) mean energy absorption density during indentation was independent of indenter size in some size ranges, and decreased with increasing indenter size in other size ranges.
\end{abstract}

\section{INTRODUCTION}

Systematic studies of snow provide useful data to natural scientists who study snow behavior under stresses from forces of nature, and to engineers who study how snow impacts the behavior of vehicles that traverse snow. Thus, quantitative measurement and description of snow mechanical behavior is desirable.

Indentation tests, common in materials science, have been used extensively in vehicle/snow interaction studies to obtain stress/displacement relationships (Jellinek, 1959; Yong and Fukue, 1977; Edens and Brown, 1991; Shoop and Alger, 1998). Snow can be viewed as a porous random heterogeneous material (Yuan and others, 2010), similar to foams (Kirchner and others, 2001) whose mechanical properties are known to be dependent on the size of the samples (Olurin and others, 2000; Kirchner and others, 2001; Onck and others, 2001; Ramamurty and Kumaran, 2004; Lu and others, 2008). In tire/snow interactions, the tire and its tread are in contact with the snow on varying length scales. The study of the size effect of snow is thus important for both materials science and application.

The mechanical properties of snow depend on microstructure, which is a product of the environment during formation, the thermal and humidity history that the snow has experienced since its formation, and the current environment. In this study, choices were made to narrow the snow types under study using two criteria: (1) availability and (2) the usefulness and applicability of results. For the latter criterion, only relatively stable types of snow were selected for study, because a fresh snowfall, by definition, does not remain on the ground for long before it metamorphoses into a more stable snow type. This stable snow is the type most likely to be encountered because it, by definition, remains on the ground in the environment for long periods. In Fairbanks, Alaska, USA, where such quasi-stable snow is available for the duration of long, cold, dry winters, the first criterion above, availability, is also nicely satisfied.

Two common and stable types of snow were selected; test parameters were varied. The variables that had the greatest effect on snow strength were pin size and snow average grain size.

Part of the motivation of this study was for tire/snow interaction models, so some terramechanics and ground vehicle research was done to ensure that the output of the test data would be in a range that would be useful to those models (Wong, 2001; Lee, 2011).

Our study is a step towards obtaining data at the mesoscale level. Tests on smaller, microscopic scales will discern the properties and orientations of individual snow grains. Tests on larger, macroscopic scales will discern the properties of the bulk snow, where edge effects and size effects have become negligible. Between these, at the mesoscale, representative volume element (RVE) may be defined. The RVE for heterogeneous materials is described in texts on heterogeneous materials (e.g. Nemat-Nasser and Hori, 1999), and is defined as the size at which the strength of snow approaches a constant (i.e. the strength at which the size effect disappears). Although the RVE was not found in this study, these tests were on a scale smaller than the RVE and larger than the microscopic scale. The concept of an RVE for snow has been suggested by Johnson and Hopkins (2005) and Yuan and others (2010).

Most earlier work tackles the larger scale. We examine $\mathrm{mm}$ to $\mathrm{cm}$ scales and we attempt to extract mechanical properties and deduce size effects at this intermediate scale.

\section{BACKGROUND}

\subsection{Earlier work}

Previous snow indentation studies have been carried out at larger scales and under different conditions than those utilized here. Seligman (1936) documented indentation tests on seasonal snow, with an eye toward avalanche studies and modeling. Yong and Fukue (1977) performed confined compression tests in natural snows, both fresh and aged, and in artificial snows that were ground from ice. Their samples were cylinders, $5 \mathrm{~cm}$ in diameter and $4.6 \mathrm{~cm}$ high. Edens and Brown (1991) investigated the correlation between microstructure and macrostructural strength by examining morphological changes under snow compression, such as coordination number, grain size, bond radius, neck length, pore size, free surface area and grains per volume. Shoop and Alger (1998) carried out tests, indenting a $20 \mathrm{~cm}$ diameter plate into artificial snow, and compared results with a computer modeling study. Additional references on snow indentation are provided by Lee (2009).

Other geometries have also been used for indentation testing. These have been based on the rammsonde cone 


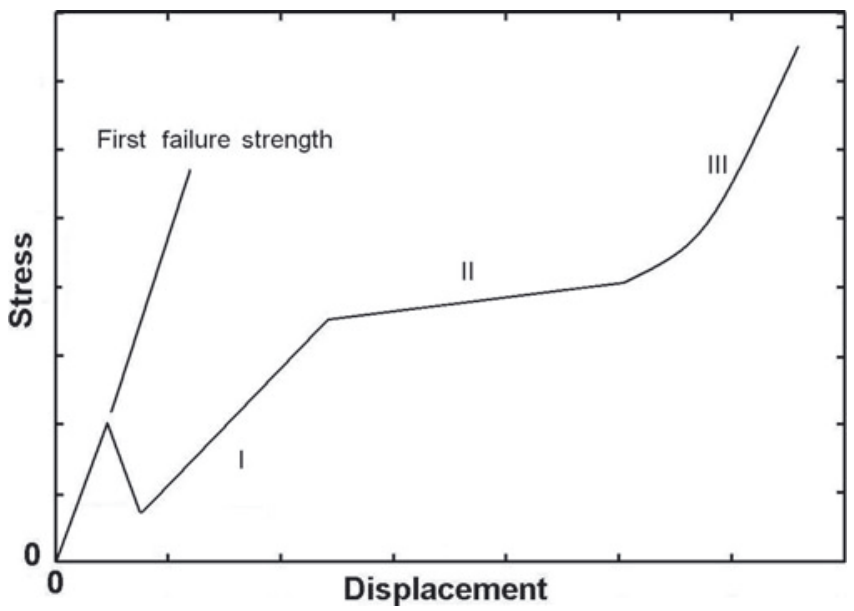

Fig. 1. Theoretical stress/displacement relationship for indentation into snow.

penetrometer that is also used in geology and soils science (e.g. Gubler, 1975; Dowd and Brown, 1986). The snow micropenetrometer (SMP) we used for snow characterization has also been used to measure snow strength (Johnson and Schneebeli, 1999; Schneebeli and others, 1999; Marshall and Johnson, 2009). Others have modified the cone to have a round tip (Floyer and Jamieson, 2010).

It has been suggested that there may be some similarities between the mechanical properties of snow and foams, since both are porous, random heterogeneous materials (Kirchner and others, 2001; Yuan and others, 2010). Thus, earlier snow studies and studies on metallic and polymeric foams (Olurin and others, 2000; Andrews and others, 2001; Kirchner and others, 2001; Ramamurty and Kumaran, 2004; Lu and others, 2008; Flores-Johnson and Li, 2010) are examined here.

Snow has also been described as a bonded granular material (McClung, 1981; Brown, 1994), especially at low, plastic deformation rates. Such deformation rates induce time-dependent ductile failure. Stereology theory is used to calculate the snow strength based on the microstructure, and the timescales are sufficiently long that the snow's metamorphism must be accounted for during deformation. In our study, deformation rates took place in the brittle region. Kinosita (1967) provides a discussion of the strain rates that yield ductile vs brittle failure in snow.

Several different mechanisms for snow deformation are compared and modeled by Mellor (1975) and Johnson and Hopkins (2005).

We apply mathematical models to the laboratory test data. Olurin and others (2000) studied metallic foams under cylindrical indentation, to examine the potential for energy absorption under impact. Flat-bottomed, cylindrical punches were used, and the results from our snow testing, which used similar cylindrical pins, are compared against these results. Andrews and others (2001) studied energy absorption by metallic foams, and performed indentation tests with various geometries. Size effects were examined, and relationships between first peak strengths and pin sizes were determined. The results from our snow tests are compared against these results, as well as results from snow models (Lee, 2009).

Others who have examined the behavior of foams utilizing small-scale testing include Onck and others (2001), Ramamurty and Kumaran (2004) and Lu and others (2008). Flores-Johnson and Li (2010) examined the behavior of polymeric foams, and Kirchner and others (2001) modeled snow as a foam of ice.

Our study builds upon the earlier work, with the following key features intended for application to ground vehicle traversal:

Size effects on mesoscales are examined.

High strain rates are used, so testing occurs fully in the brittle region.

Natural snows are used.

Snow selection is based on what is found most commonly in populated regions.

Flat-bottomed cylindrical indenters are used.

\subsection{Indentation model}

The indentation model developed by Lee (2009) uses cohesion, internal friction angle and hydrostatic-stress/volumetric-plastic-strain relationships in a plasticity model to predict stress/displacement curves. The curves are classified into three zones, as shown in a theoretical curve in Figure 1.

First, the stress rises to a peak, before an immediate loss of strength. This first peak is called the first failure strength of the snow. After these first transient effects, the indentation proceeds through three zones discussed in Lee's (2009) model. Zone I exhibits a linear (but plastic) rise in stress as the indenter proceeds through the snow. During zone I, the indenter accumulates a densified zone beneath it called a pressure bulb. Muro and O'Brien (2004) cite several papers (e.g. Yosida and others, 1956; Muro and Yong, 1980) that discuss this densification zone. Both an initial first peak and a densification zone are also mentioned for a round-tipped penetrometer (Floyer and Jamieson, 2010) and for a vertically loaded plate (Shoop and Alger, 1998).

At the transition to zone II, the pressure bulb has reached its maximum size and it proceeds to move through the snow together with the pin, usually with a slight increase in resistive force due to snow hardening. The average stress during zone II is henceforth called the 'plateau strength'.

Zone III is the region where the pressure bulb reaches the bottom of the snow and further compacts. This only occurs during deep indentation, and is provided by the bottom of the snow container in the laboratory, or the frozen soil or street surface in a 'real world' application. This is called a densification (finite depth) zone.

\subsection{Plateau strength analysis of foams}

Olurin and others (2000) performed similar indentation tests on open-cell aluminum foams and calculated the resistive strength during indentation, separated into two components, a crushing term and a tearing term. The crushing term relates to material being compacted beneath the pin, and is proportional to the leading-face surface area. The tearing term relates to damage caused to the snow by the circumferential edge of the pin as it creates new surface while driving into the snow. It is therefore proportional to the pin circumference. Olurin reasoned that

$$
\begin{gathered}
F=F_{\text {crushing }}+F_{\text {tearing }} \\
F=\pi r^{2} \sigma_{\text {crush }}+2 \pi r \gamma_{\text {tear }} \\
\frac{F_{\mathrm{PL}}}{\pi r}=\sigma_{\text {crush }} r+2 \gamma_{\text {tear }}
\end{gathered}
$$




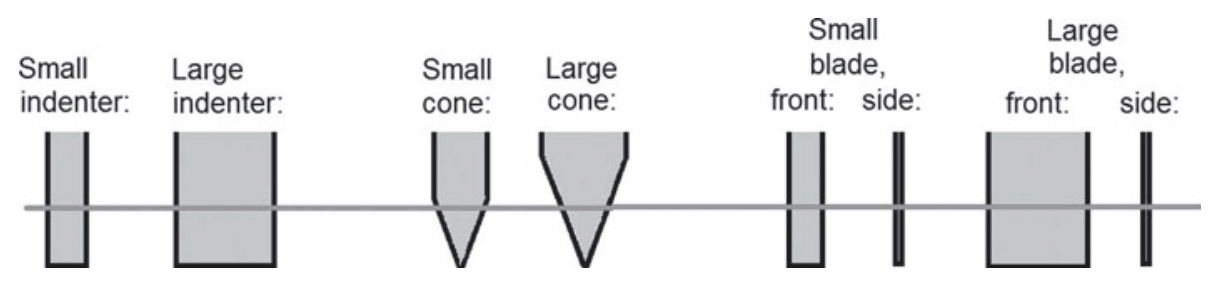

Fig. 2. Size effects of different indenter geometries.

where $F_{\mathrm{PL}}$ is the plateau strength (units of force length rather than stress), $r$ is the pin radius and $\sigma_{\text {crush }}$ and $\gamma_{\text {tear }}$ are the crushing and tearing terms respectively. Thus, a plot of $F_{\mathrm{PL}} /$ $(\pi r)$ as a function of pin radius is expected to be linear, with the slope being the crush strength, and the intercept giving the tearing strength.

\section{EXPERIMENTAL PROCEDURES}

\subsection{Collection and storage of snow}

Virgin (undisturbed), metamorphically stable, dry snow was collected in and around Fairbanks in locations far from sources of contamination, at temperatures of -9 to $-30^{\circ} \mathrm{C}$. Typically, snow was gathered a week after the previous snowfall. This gave adequate time for sufficient metamorphism to provide roughly uniform grains of approximately spherical shape. Air temperature, snow surface temperature and snow pit-temperature were recorded at each snow collection site.

Two types of snow were collected. The first was finegrained (average grain size $<1 \mathrm{~mm}$ ) snow such as occurs near the surface of a snowpack. This is snow that has fallen within the previous month or so. The second was coarsegrained (average grain size $>1.5 \mathrm{~mm}$ ) depth hoar such as occurs at depths greater than $20 \mathrm{~cm}$ under a surface cover and typically where there is ice over liquid water, such as on a river or a pond. This is snow that has fallen at least 3 months earlier, and has been kept at a thermal gradient by exposure to liquid water beneath the ice, and insulated above by fresher snow layers.

Samples were collected in chilled plastic containers and transported to laboratory freezers in a cooler. Laboratory freezers were maintained at $-30^{\circ} \mathrm{C}$, cold enough to slow metamorphism and sintering to a very low rate (after 6 months in storage, little sintering had taken place among the snow grains). Storage time ranged from $<1$ day to 6 months.

\subsection{Snow characterization}

Snow was selected and characterized both in situ and in the laboratory using multiple methods, to ensure that snow sample-to-sample variation was minimal. The first in situ test utilized a high-resolution SMP. Samples were then removed from the snow bank and measured, weighed and sieved on-site to obtain density and grain-size distribution. Specimens collected and brought to the laboratory were additionally characterized via optical inspection with a light microscope and CT (computed tomography) scanning using three-dimensional X-ray microtomography.

The SMP used was developed by Johnson and Schneebeli (1999) for use by avalanche researchers. In this study, it was used to check snow properties in situ so that appropriate snow samples could be selected. Output of the SMP is penetration force and texture index, which is an empirical number used to describe the snow grain geometry. It is defined as the ratio of mean grain size $(\mathrm{mm})$ to density $\left(\mathrm{kg} \mathrm{m}^{-3}\right)$.

The density was measured at the field collection sites using a graduated cylinder of known mass, hanging from a spring scale. This gave a quick, rough estimate of density that was later compared with the density obtained from the CT scan images.

Grain-size distribution was also obtained by sieving, with sieves of $1.4,1$ and $0.425 \mathrm{~mm}$. From this sieving, average grain sizes were estimated to be $1 \mathrm{~mm}$ for the fine-grained snow and $2.2 \mathrm{~mm}$ for the coarse-grained snow.

CT scanning took place in a cold room, and samples were scanned before and after testing at $23.7 \mu \mathrm{m}$ resolution using parameters as recommended by Yuan (2007).

The SMP readings, density measurements, weighing and sieving and CT scanning all established baseline microstructures for different natural snows in their natural state, using the International Classification for Seasonal Snow on the Ground (ICSSG; Fierz and others, 2009).

\subsection{Establishment of testing parameters}

\subsubsection{Selection of snows}

We determined that the two snow types occurring with high regularity in aged snowpacks in Fairbanks were medium rounded grains near the surface (the top 15-20 cm), with coarse faceted rounded particles beneath the fine-grained layer, as described in the ICSSG (Fierz and others, 2009). Measured snow densities ranged from 148 to $251 \mathrm{~kg} \mathrm{~m}^{-3}$, with the fine-grained snow generally ranging from 150 to $170 \mathrm{~kg} \mathrm{~m}^{-3}$ and the coarse-grained snow from 200 to $230 \mathrm{~kg} \mathrm{~m}^{-3}$. The fine-grained snow had an average grain size less than $1 \mathrm{~mm}$, while the coarse-grained snow had an average grain size less than $1.5 \mathrm{~mm}$. Texture index values were found to be $\sim 3-4.5$ for fine-grained snow, and $\sim 5-7$ for coarse-grained snow. Observations and measurements were similar for three consecutive winters, 2008/09, 2009/ 10 and 2010/11, enough to instill confidence that test results from snows of different winters were comparable.

\subsubsection{Pin selection}

Cylindrical indenters were chosen because they are most typically used in vehicle-terrain studies. They also have several advantages that make them ideally suited to this study. First, to study size effects, it is necessary to have an indenter for which the size ratios among the different linear dimensions do change with changing indenter size. To illustrate, one of the pieces of data captured in this study was the initial failure strength of the snow, which is a function of initial geometry. The differences among initial geometry due to size are illustrated in Figure 2.

Below the green line, a larger radius and a smaller radius cone present the same leading-face geometry to the test material (the snow). Therefore, a cone tip test cannot yield a 


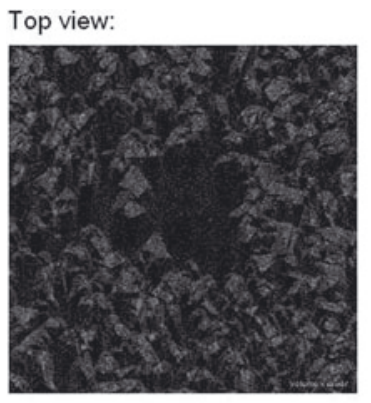

Front view:

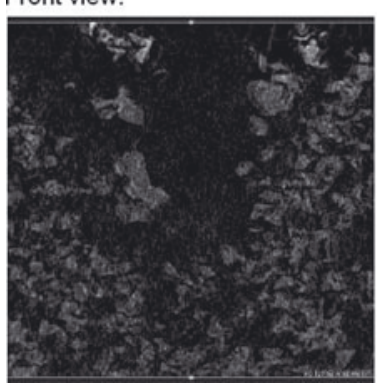

Side view:

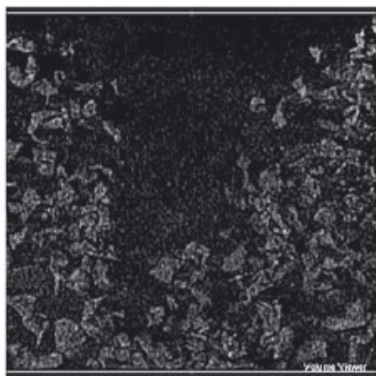

Fig. 3. CT scans of indented snow (white is ice).

size effect for initial failure strength. A change in cone angle would change the tip geometry, but any differences shown in such a study would be due to a change in angle as well as linear measurements.

For a blade, the linear dimensions change in one direction, but not in the other (the blade thickness). Therefore, a blade test yields a less pronounced size effect for initial failure strength. Other geometric cross sections will work as well as a circular cylinder, but a circular cylinder was chosen to simplify the calculations, and to avoid adding vertical edges.

\subsubsection{Confirmation of indentation model using CT scans}

The CT scan images confirmed that densification did occur during snow indentation. This confirms the theory described in Section 2.2 and further discussed in Section 4.1. Figure 3 shows top, front and side cross-sectional views of a column of snow after indentation. The post-processing of CT scans enables analysis of snow particles slice by slice. Figure 4 shows a lower slice of a snow sample before and after indentation with a $12.7 \mathrm{~mm}$ diameter pin.

Using these images, the original density of this snow sample was found to be $186 \mathrm{~kg} \mathrm{~m}^{-3}$ ( $80 \%$ porosity), and the density of the region directly beneath the indenter was found to be $649 \mathrm{~kg} \mathrm{~m}^{-3}$ (29\% porosity). The change in density indicates whether the pin is compacting the snow or drilling through the snow. The larger the pin, the more compaction took place. Figure 5 shows the comparison for a $6.35 \mathrm{~mm}$ pin.

Using these images, the original density of this sample was $262 \mathrm{~kg} \mathrm{~m}^{-3}$ (71\% porosity), and the compressed density under the pin after indentation was $270 \mathrm{~kg} \mathrm{~m}^{-3}(70 \%$ porosity). As discussed in Section 4.1, less compaction took place with smaller indenter-size to average grain-size ratio. More compaction can be seen in Figure 4 than in Figure 5 (the higher percentage of white regions indicates a higher density of ice). Both Figures 4 and 5 are consistent with the theory, described in Section 2.3, of a densification zone beneath the pin.

The CT scanning also provides a criterion for snow container size during testing as follows. From the postindentation scans, the horizontal slices beneath the indenter were analyzed. For a given snow slice, areal density was measured, of circles and annular regions of increasing size, centered on the spot directly beneath the middle of the indenter. When the density of an annular region was about the density of virgin snow, it was determined that the pressure bulb had been contained within the inner circle. After this test was performed with the largest pin sizes and with a safety factor of 1.5 , it was determined that with the container diameter four times the pin diameter, containment effects were negligible.

\subsubsection{Initial sensitivity studies}

Before formal testing began, sensitivity studies were performed to determine which parameters significantly affected the snow behavior and which did not. After the sensitivity studies were performed, tests were selected to vary only the parameters that would yield results of interest.

Parameters that were varied in the initial sensitivity studies were:

Snow container diameter (Section 3.3.3): It was found that snow container diameter needed to be at least four times the pin diameter in order not to have confinement effects. Confinement effects were determined as being

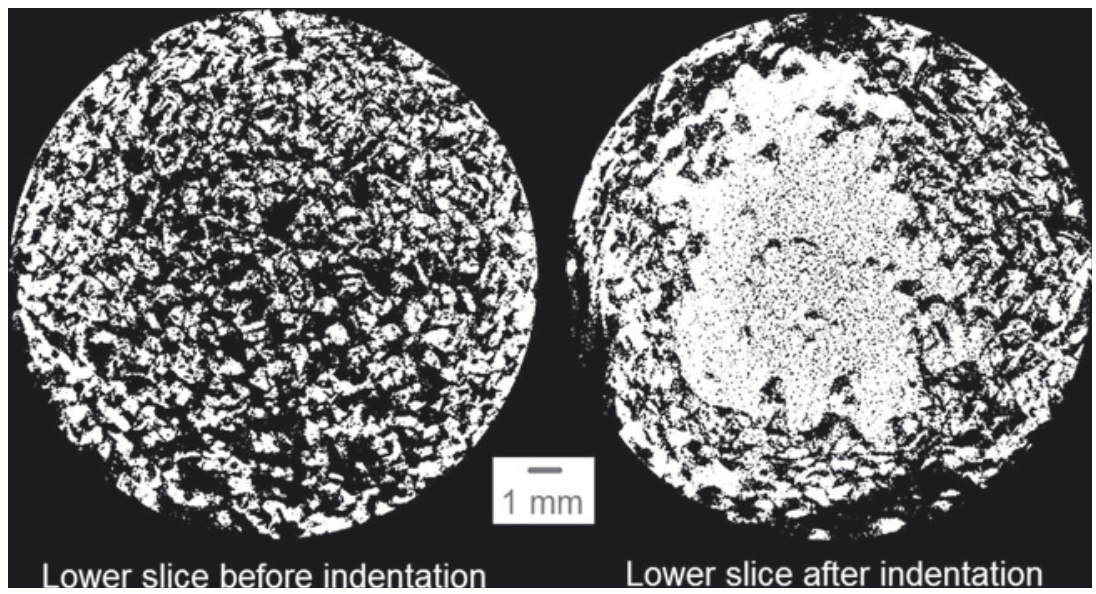

Fig. 4. Cross sections of CT scan of indented snow, $12.7 \mathrm{~mm}$ indenter (white is ice). 


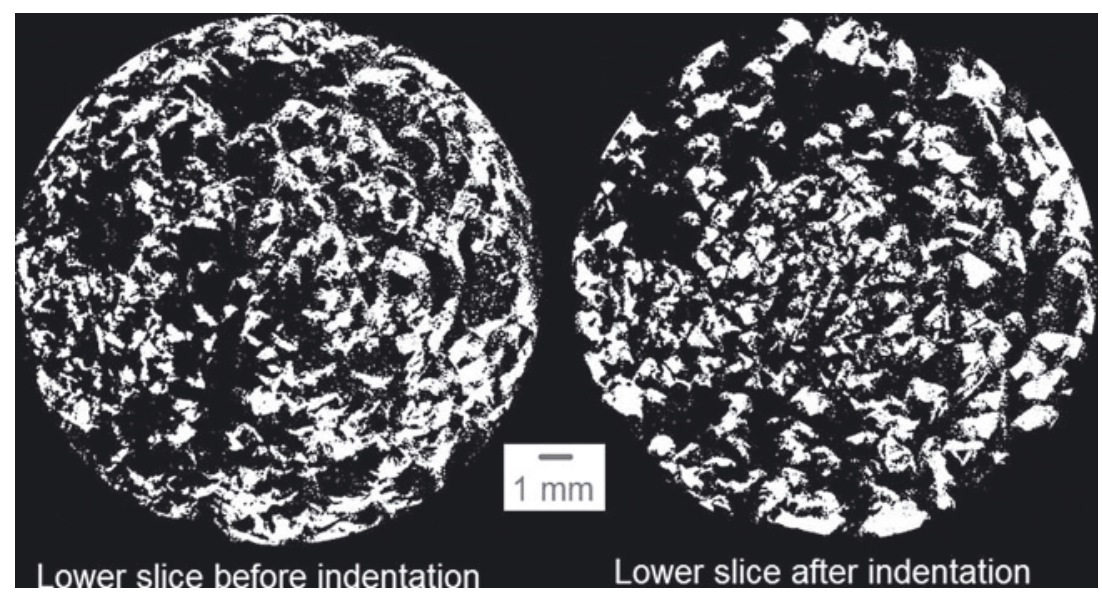

Fig. 5. Cross sections of CT scan of indented snow, $6.35 \mathrm{~mm}$ indenter (white is ice).

present when an increase in container diameter showed a decrease in apparent snow strength. When a further increase in container diameter showed no apparent change in snow strength, that diameter was determined as being sufficiently large. This was confirmed by CT scanning.

Snow depth: A depth of $20 \mathrm{~mm}$ was chosen because $10 \mathrm{~mm}$ was too shallow to achieve the plateau strength, and deeper snow took more time and resources than necessary.

Indentation depth: Indentation needed to reach zone III in order to achieve results of interest. A depth of $10 \mathrm{~mm}$ was chosen because, with a snow depth of $20 \mathrm{~mm}$, the first peak and all three indentation zones can be observed within $10 \mathrm{~mm}$ of indentation.

Snow average grain size: No variability due to grain size was observed in the first peak, but differences were observed in zones I and III, so this variation was retained for the formal study.

Indentation speed: No difference was observed in snow mechanical behavior between indentation speeds of 2 and $5 \mathrm{~mm} \mathrm{~s}^{-1}$, so this variation was removed from the formal study. However, the data collected during these tests have proved valuable, so they were kept for analysis.

Load cell used for test: A small load cell was required for higher sensitivity in the smaller pin tests; a larger load cell was required to cover the range of greater accumulated force in the larger pin tests.

\subsection{Tribometer set-up}

A CETR-UMT tribometer was used for indentation testing. This tribometer has high-resolution load cells and is easily adapted to individual tests.

Two different load cells were used for their different capacities: one had a range of $5-500 \mathrm{mN}$ and a resolution of $0.05 \mathrm{mN}$; the other had a range of $2-200 \mathrm{~N}$ and resolution of $0.01 \mathrm{~N}$. The test region was maintained at a temperature of $-20^{\circ} \mathrm{C}$ using a low-temperature forced airstream, set to an output of $-40^{\circ} \mathrm{C}$. The reason for this temperature difference is that the enclosure has some inevitable leakage due to the necessity of openings for the various interfaces with the tribometer.
Figure 6 shows an indentation test in progress (the enclosure was opened only for photography purposes; in actual testing, it remained closed). This example shows a $3.175 \mathrm{~mm}$ pin being indented into a small amount of snow. As discussed in Section 3.3.3, larger containers were used for the larger pin diameters, to eliminate any confinement effects.

The sample holders were made of flat-bottomed plastic cups to minimize thermal contamination, and the pins were machined of aluminum, which has a good balance of light weight to minimize inertial effects, and high stiffness so that only the effects of the snow are captured during the indentation. In other words, the stiffness of the aluminum was considered to be infinite compared with the stiffness of the snow.

\subsection{Test parameters}

Tests were carried out with the parameters shown in Table 1. Some variations were made due to logistical constraints, and were not part of the variations under study.

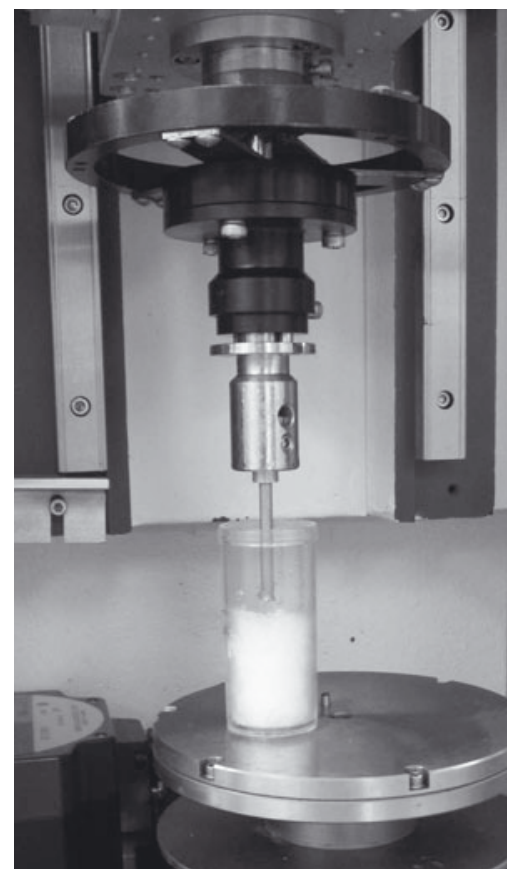

Fig. 6. Indentation test set-up. 


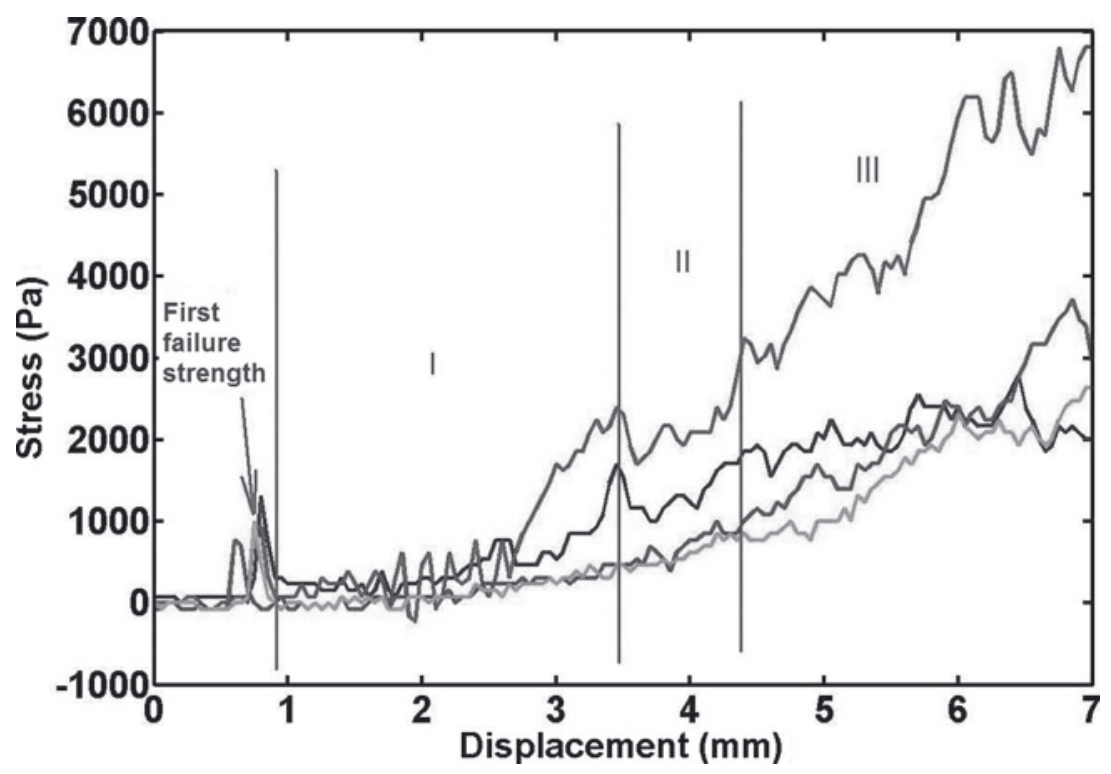

Fig. 7. Stress/displacement curves for $12.7 \mathrm{~mm}$ pin indentations into fine snow.

Varying different parameters and repeating tests with ambiguous results, $\sim 400$ indentation tests were performed in total. Of these, only those that gave clear results and the values needed for a given calculation (e.g. plateau strength for a plateau strength calculation) were used in the data processing.

The ductile-to-brittle transition normal strain rate for snow is $\sim 10^{-4} \mathrm{~s}^{-1}$ (Kirchner and others, 2001). Strain rates for this set of testing were selected to be well above this strain, but low enough to reduce inertial effects. Thus, all tests were well within the brittle range.

In total, 118 sets of tests were performed, with 3-6 runs of each test. Of these 600-odd data points, 100-200 were used for each data report.

\section{RESULTS}

\subsection{Stress/displacement curves}

The stress/displacement curves qualitatively reflected the model described in Section 2.2. However, not all three zones were present in all cases. The larger the indenter size relative to the average snow grain size, the more distinct the zones. At the limit of very small indenter-size to snow grain-size ratio, the first peak became unrepeatable as it depended too highly on initial placement of the pin relative to the snow grains. Also, for small indenters, the effect was more that of the pin drilling rather than of the cylinder compressing, and no pressure bulb accumulated, so that zone I was not represented. At the limit of deep snow, where the pressure bulb did not contact the bottom surface, zone III did not occur. At the limit of very shallow snow, zone II was not represented because the pressure bulb hit the bottom before it attained its maximum size.

Figure 7 shows the stress/displacement relationship for four $12.7 \mathrm{~mm}$ pin indentations into fine-grained snow. The horizontal axis is the pin displacement into the snow. The vertical axis is the stress, i.e. the resultant force detected by the load cell coupled to the pin, divided by the crosssectional area of the pin.

Figure 8 shows the stress/displacement relationships for two different pin sizes and two different snow types.

As is discussed in Sections 4.2 and 4.3, the overall forces are higher for the smaller pin. It is also qualitatively observed that zones I and III do not occur for the $3.175 \mathrm{~mm}$ pins, since snow was not compacted in those tests. The curves show a transition from the initial peak directly to zone II. Moreover, we see that the $3.175 \mathrm{~mm}$ indentation into fine-grained snow yielded a smoother curve than the indentation into the coarse-grained snow, because the pin was large enough with respect to the grain size to read an average force over multiple snow grains. In contrast, the indentation into coarsegrained snow yielded a much less consistent force because the indenter size was on the same order of magnitude as the snow grain size. Thus the behavior of individual snow grains was detected.

Table 1. Indentation test parameters

\begin{tabular}{|c|c|c|c|}
\hline Parameter & Parameters varied for study & Unit & Variation part of study? \\
\hline Indentation pin diameter & $3.175,6.35,9.525,12.7,34,42$ & $\mathrm{~mm}$ & Yes \\
\hline Snow depth & 20 & $\mathrm{~mm}$ & No \\
\hline Indentation speed & 2,5 & $\mathrm{~mm} \mathrm{~s}^{-1}$ & No \\
\hline Snow type & $\begin{array}{l}\text { 1. Fine-grained, average grain size } 1 \mathrm{~mm} \text {, density } 148-251 \mathrm{~kg} \mathrm{~m}^{-3} \text {; } \\
\text { 2. Coarse-grained, average grain size } 2.2 \mathrm{~mm} \text {, density } 200-230 \mathrm{~kg} \mathrm{~m}^{-3}\end{array}$ & & Yes \\
\hline Load cell used for test & $200 \mathrm{~N}$ capacity with $0.01 \mathrm{~N}$ resolution; $500 \mathrm{mN}$ capacity with $0.05 \mathrm{mN}$ resolution & & No \\
\hline
\end{tabular}




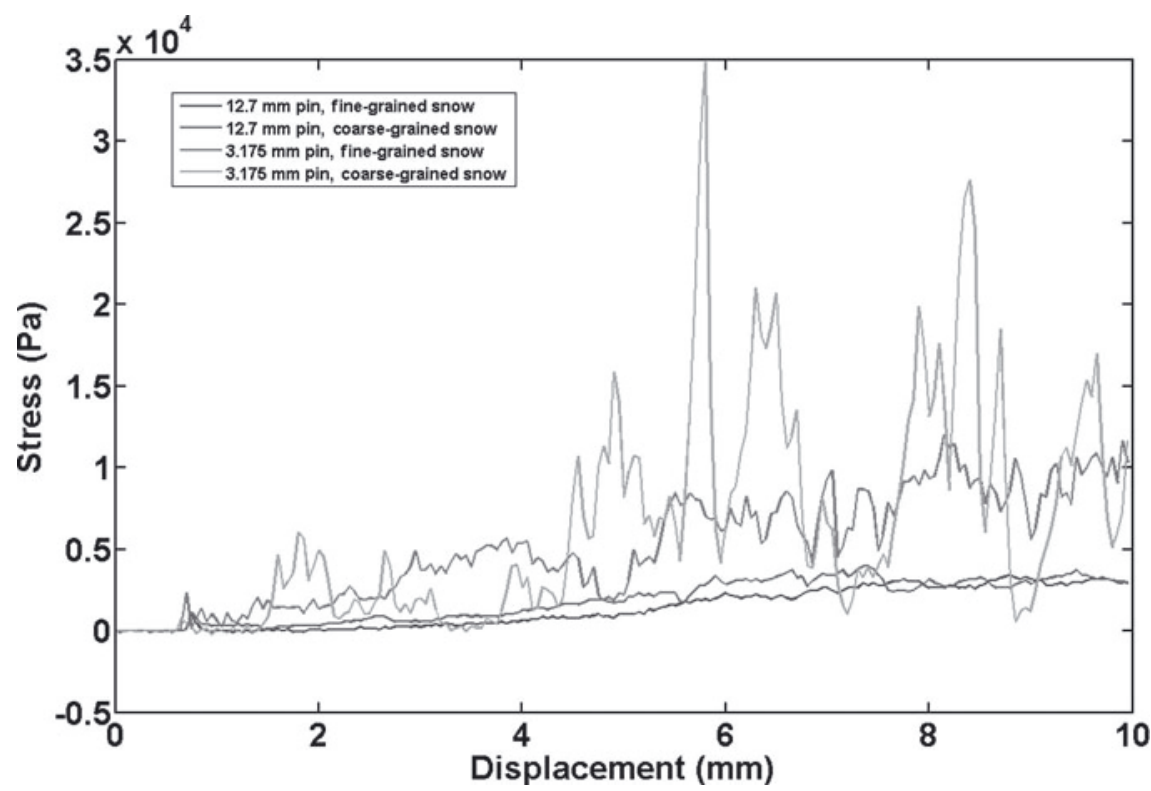

Fig. 8. Stress/displacement curves comparing pin sizes and snow types.

Figure 9 shows the same $12.7 \mathrm{~mm}$ indentation data as in Figure 8 , but with the $3.175 \mathrm{~mm}$ data removed so that the detail of the larger pin indentation may be seen.

Here, where the indenter size is sufficiently large that the ratio of indenter size to snow grain size is much greater than 1 in both cases, both graphs look similar.

\subsection{First peak strength}

The size of the indenter and the average grain size of the snow were varied to determine their effects on first peak strength. It was found (Fig. 10) that the larger the indenter, the lower the first peak failure strength. On $\log _{e}$ scales, a linear relationship is evident so that a power law is apparent:

$$
\sigma_{\mathrm{fs}}=k A^{-\gamma}
$$

where $\sigma_{\mathrm{fs}}$ is the failure stress, $\gamma$ is a dimensionless material property, $A$ is the pin area and $k$ is a constant.
Table 2 shows results obtained for $\gamma$ against other parameters. Each test ID represents four to six indenter sizes, with three to six indentations repeated for each size.

The average value of $\gamma$ is 0.83 (with a coefficient of variation (COV) of 0.16) for fine-grained snow, and 0.85 (with a COV of 0.23) for coarse-grained snow. The average value for both snow types is 0.84 , with a COV of 0.15 .

The actual values of first peak strength had high test-totest variability (as high as an order of magnitude), even when the same snow sample was used and all other test conditions were ostensibly the same. The source of this variability is not understood, but it is specific to the first peak strength values over time. On the same day, first peak strength values were highly repeatable. Also, plateau strength values (Section 4.3) did not show the same day-to-day variability. However, all the different sets of data yielded the fairly consistent values of $\gamma$ shown in Table 2 .

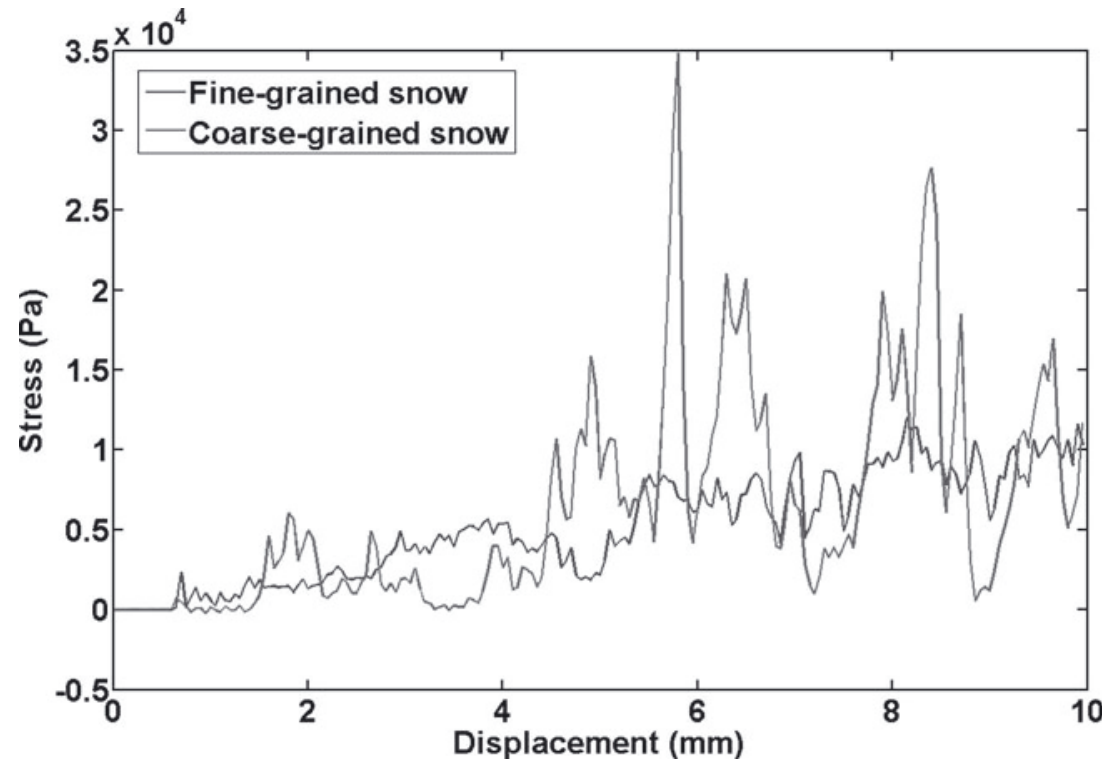

Fig. 9. Stress/displacement curves for $12.7 \mathrm{~mm}$ pin indentations, comparing two different snow types. 


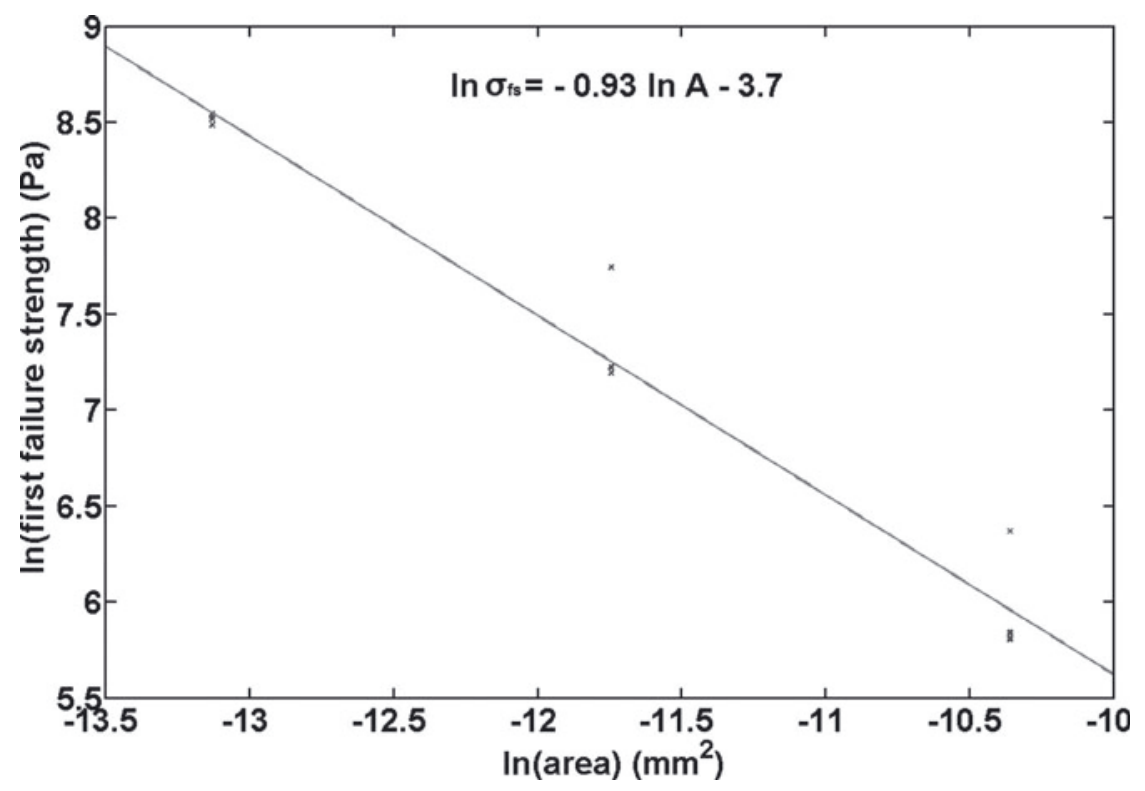

Fig. 10. Example of first failure strength data, fine-grained snow.

The other size relationship explored was that of grain size. Identical tests were performed on both fine- and coarse-grained snow. The first peak strengths had the same mean values and same COV for both fine- and coarsegrained snow, although grain size did affect other snow properties as discussed in Section 4.1.

\subsection{Plateau strength (zone II)}

The mean plateau strengths for several different test sets are given in Table 3, in which $\sim 150$ tests are represented, with each test yielding one data point. Typical results are shown in Figure 11a and b. Each pin diameter in each test set was tested four times, but not all gave a measurable plateau.

About three-quarters of the plateau strengths were determined 'semi-automatically', by criteria based on the specific test run. The plateau was defined by the rule: 'when the moving average of $X$ points changes by more than $Y$ and remains stable for $Z$ data points, then $Z$ is called the plateau'. X, Y and Z were manually selected on a test-by-test basis, due to the large test-to-test variation. A quarter of the resulting plateau strengths came out completely inappropriately; plateau ranges were hand-selected using careful visual judgment.

The raw data for the plateau strengths shows a monotonically decreasing trend with increasing diameter. With such a large spread and with only four different diameters

Table 2. Exponent from a range of tests

\begin{tabular}{lccc}
\hline Test ID & Test date & Snow type, month collected & $\gamma$ \\
\hline 0 & 14 Jul 2009 & Fine-grained, Mar 2009 & 0.97 \\
2 & 30 Dec 2009 & Fine-grained, Dec 2009 & 0.62 \\
3 & 6 Jan 2010 & Fine-grained, Dec 2009 & 0.92 \\
4 & 16 Jan 2010 & Fine-grained, Dec 2009 & 0.76 \\
6 & 18 Mar 2011 & Fine-grained, Dec 2010 & 0.93 \\
7 & 18 Mar 2011 & Fine-grained, Dec 2010 & 0.80 \\
1 & 14 Jul 2009 & Coarse-grained, Mar 2009 & 0.98 \\
5 & 16 Jan 2010 & Coarse-grained, Mar 2009 & 0.71 \\
\hline
\end{tabular}

yielding plateau strengths, the mathematical form of the relationship is difficult to determine. However, once the data are analyzed for material properties as discussed in Section 2.3, the plot output from these calculations is much more useful. Representative results of plateau force, $F_{\mathrm{PL}} /(\pi r)$ (Section 2.3) for two different test sets are shown in Figure 12a and b. All test sets reflect multiple days of testing, often in different years, so the spread of data is quite large. However, this enabled more data points to be used, ensuring broad representation. Each data point represents one test.

Results from the four datasets that displayed a linear trend are shown in Table 4, in which $\sim 150$ tests are represented, with each test yielding one data point. The apparent negative values of the shear term can be taken to be zero. This seems to indicate that the tearing term is indeed negligible.

\subsection{Absorption of energy}

Total energy absorption for each indentation, from first contact with the snow to the completion of the test (in this case, $10 \mathrm{~mm}$ indentation), was calculated by taking the area under the force/displacement curve. The entire curve was used because energy absorption, unlike first peak strength or plateau strength, is a property that is cumulative with indentation depth. The deeper the snow, the more stable (with respect to depth) is the measured energy absorption density, since the transient initial effects from the first peak and zone I become much smaller than the effects from the plateau region of zone II.

To normalize against geometric factors and arrive at a dimensionless number, the volumetric absorbed energy density was calculated by dividing the absorbed energy by the volume of snow displaced and by Young's modulus for ice, for which we used $9 \mathrm{GPa}$ (Schulson, 1999). Figure 13a and $\mathrm{b}$ show results from all tests, of energy absorption density, with no outliers removed. Some smaller scatter was expected in these data due to the cumulative nature of the calculation of the energy absorption. Note that energy absorption data could be collected for the two largest pin sizes, 34 and $42 \mathrm{~mm}$, yet data for these two pin sizes yielded neither a first peak, nor a plateau strength. Additionally, note 

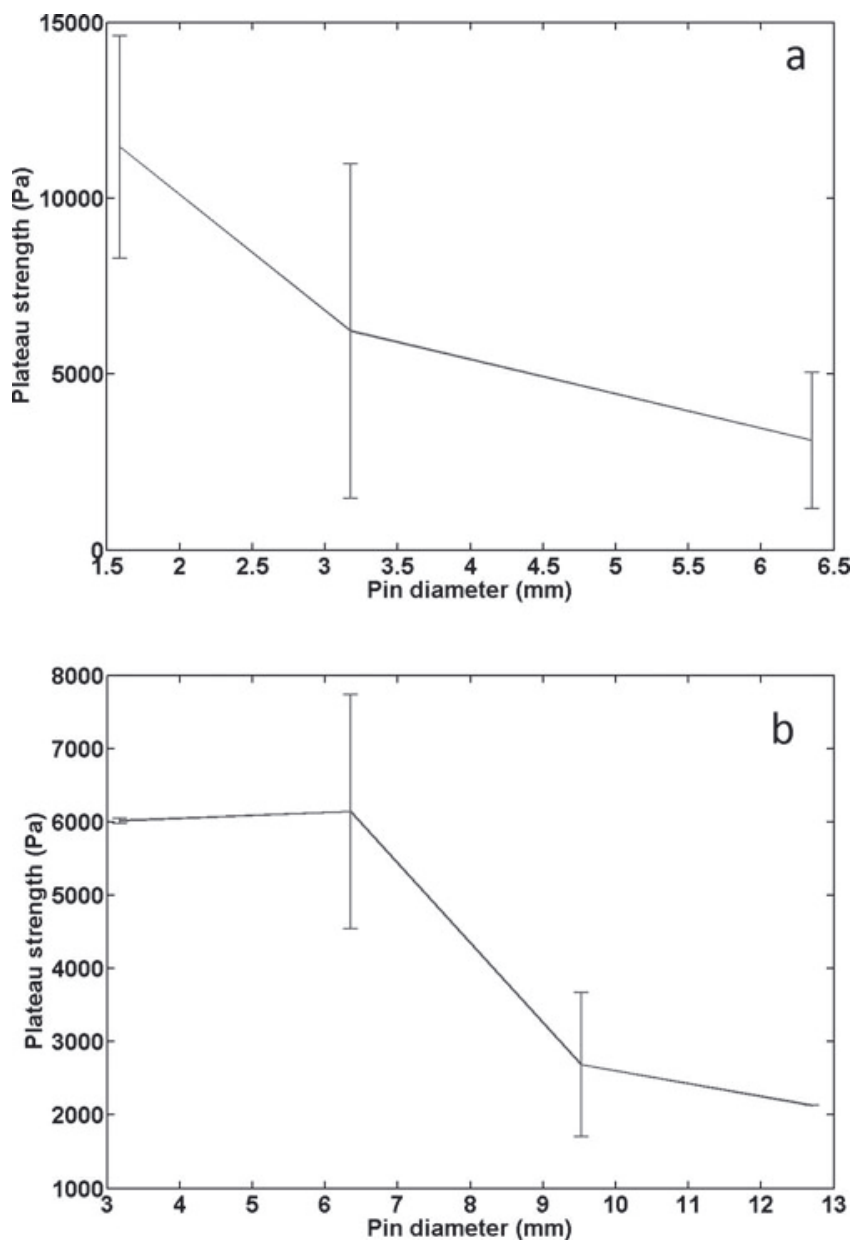

Fig. 11. Relationship between plateau strength and pin diameter, for (a) fine grained snow and (b) coarse-grained snow (there is only one data point at $12.7 \mathrm{~mm}$ ).

that fine-grained snow showed greater scatter than coarsegrained snow. This indicates a greater variability of snow behavior in fine-grained snow than coarse-grained.

It was found that the average energy absorption density was $3.4 \times 10^{-7}$ for fine-grained snow, and $4.1 \times 10^{-7}$ for coarse-grained snow. These preliminary results suggest that for cylindrical indentation in this size range, energy absorption density was constant with respect to diameter for fine-grained snow, and decreased with increasing diameter for coarse-grained snow. Note that this decrease was not linear, flattening out to suggest energy absorption independence of size at larger diameters.
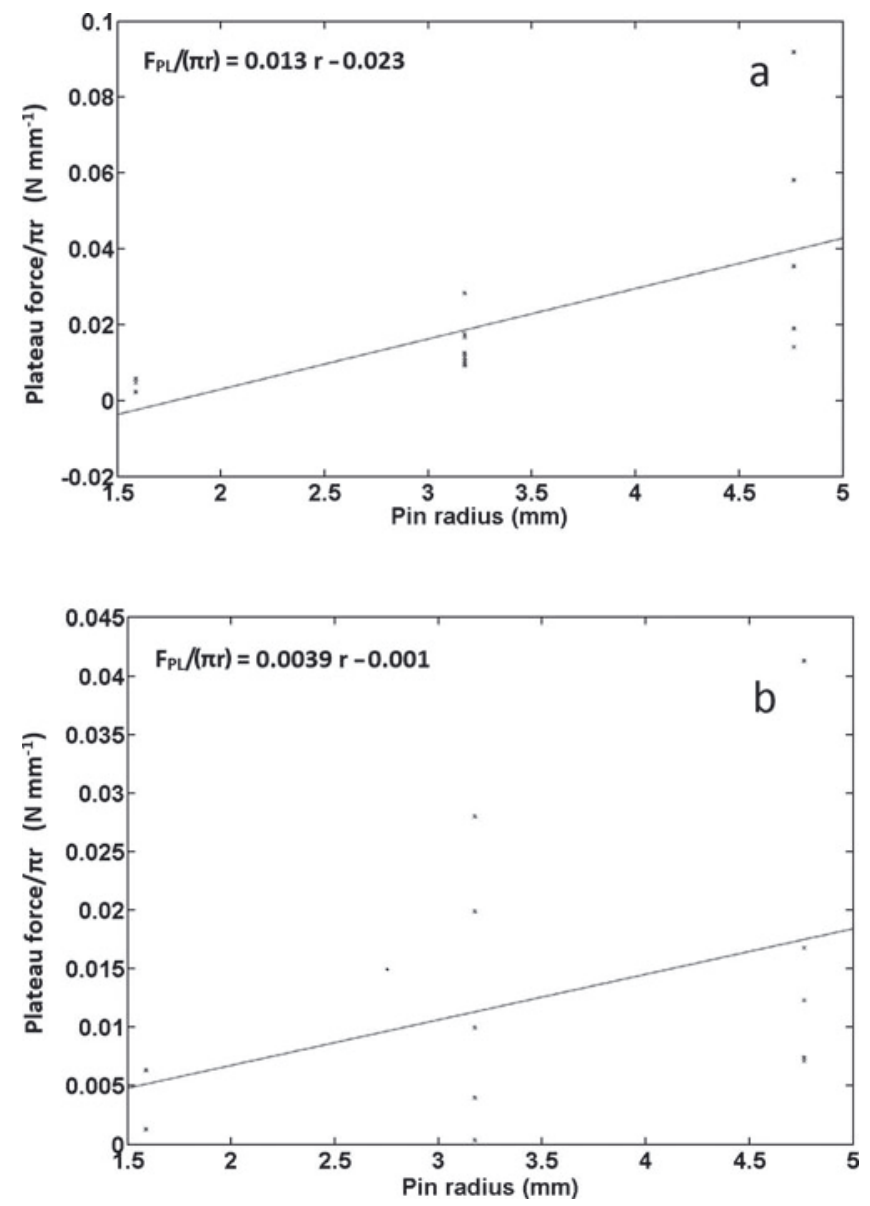

Fig. 12. (a) Plateau force $/ \pi r$ as a function of pin radius at $2 \mathrm{~mm} \mathrm{~s}^{-1}$ for (a) fine-grained and (b) coarse-grained snow.

\section{DISCUSSION}

\subsection{First peak strength}

First peak snow strength was highly dependent upon surface conditions and showed high test-to-test variation. Even when known factors were carefully controlled, a different day would yield different first peak strengths, even though the spread of first peak data for a given day was very small. This suggested variations were due not to the equipment or operator, but to intrinsic changes that occur in the surface properties of the snow with storage time. The variability between tests was much smaller for plateau strengths, suggesting that changes that led to the high variability in initial failure strength did not affect snow behavior beyond the first failure. Once the pressure bulb had accumulated,

Table 3. Mean plateau strengths from a range of tests

\begin{tabular}{|c|c|c|c|c|}
\hline \multirow{3}{*}{$\begin{array}{l}\text { Pin diameter } \\
\mathrm{mm}\end{array}$} & \multicolumn{2}{|c|}{ Fine-grained snow } & \multicolumn{2}{|c|}{ Coarse-grained snow } \\
\hline & Mean plateau strength & $\mathrm{COV}$ & Mean plateau strength & COV \\
\hline & $\mathrm{Pa}$ & & $\mathrm{Pa}$ & \\
\hline 1.588 & 15700 & 0.63 & No test performed & No test performed \\
\hline 3.175 & 5620 & 0.74 & 6010 & 0.67 \\
\hline 6.350 & 6940 & 0.78 & 4010 & 0.69 \\
\hline 9.525 & 5800 & 1.06 & 3360 & 0.64 \\
\hline 12.700 & 2560 & 0.21 & 3000 & 0.31 \\
\hline
\end{tabular}



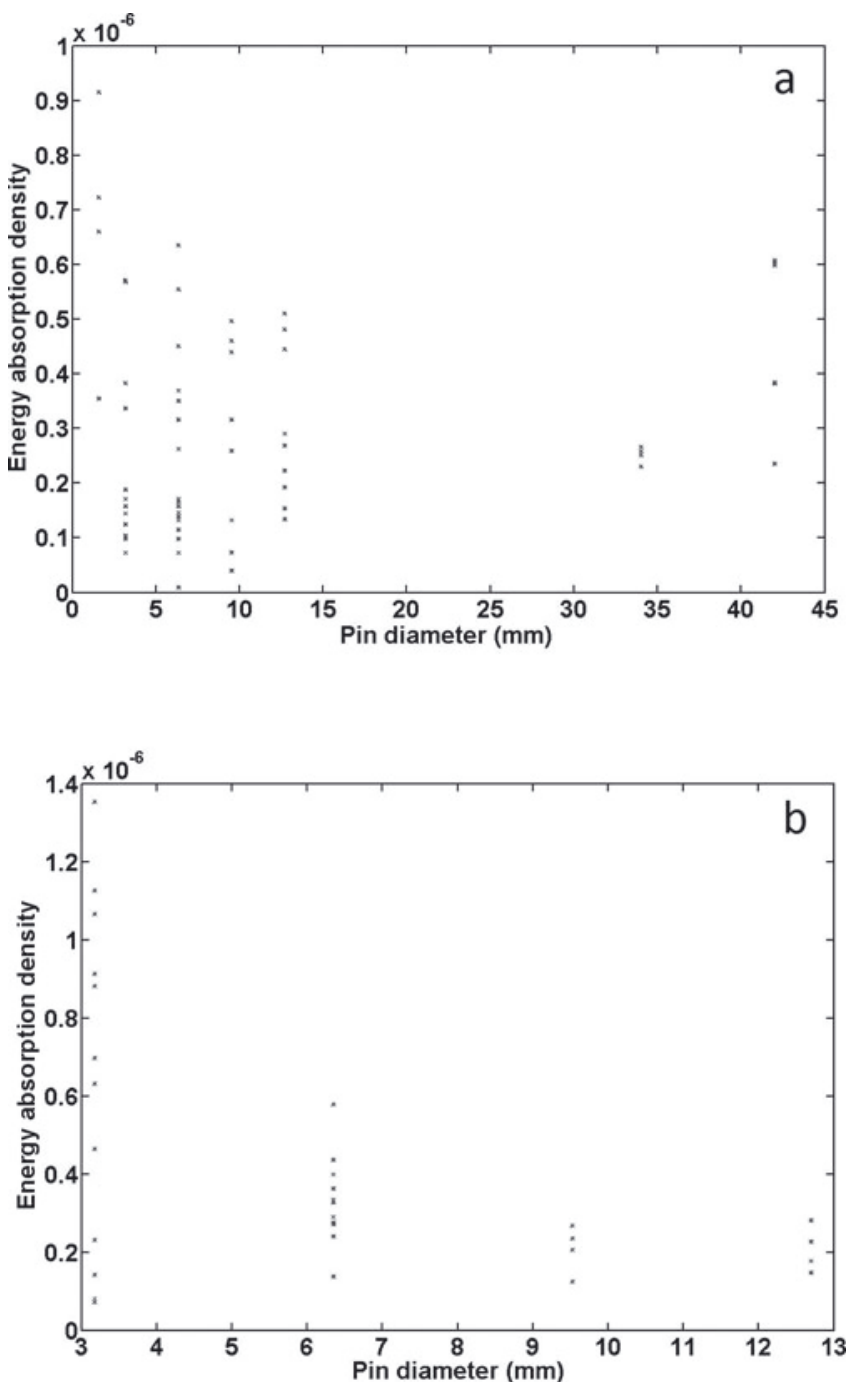

Fig. 13. Energy absorption density during pin indentation into (a) fine-grained and (b) coarse-grained snow.

the bulb itself exhibited volumetric properties that were consistent from test to test. By the time the test had reached zone II, the transient effects of the initial conditions had effectively disappeared and the plateau strength better reflected the intrinsic properties of the snow.

The value of the exponent in the power law relationship between first peak strength and pin area was consistent from snow sample to snow sample, so although the absolute first peak strength was highly sample-dependent, the magnitude of the size effect was consistent.

The average value of the power law exponent for both snow types is 0.84. As a comparison, the exponent for brittle foams was estimated to be 0.5 (Gibson and Ashby, 1999), lower than that for the snow tested, indicating that the size effect displayed by first peak strength in snow is greater than that for brittle foams.

\subsection{Plateau strength}

The plateau strengths used to calculate the crush strength of snow were repeatable and are believed to reflect fundamental properties of the bulk snow. The plateau strength is also of more use to engineers and scientists, as it is reasonable to expect a tire, ski, sled runner, animal paw or hoof to compress the snow a small amount before coming to a stop after a certain compression amount. What limits this
Table 4. Compaction and shear terms from a range of tests

\begin{tabular}{cccc}
$\begin{array}{c}\text { Test } \\
\text { ID }\end{array}$ & $\begin{array}{c}\text { Snow average } \\
\text { grain size } \\
\mathrm{mm}\end{array}$ & $\begin{array}{c}\text { Mean value of compaction } \\
\text { term, } \sigma_{\text {crush }}\end{array}$ & $\begin{array}{c}\text { Mean value of } \\
\text { spa }\end{array}$ \\
\hline 1 & 1.0 & 13 & $\mathrm{~N} \mathrm{~mm}^{-1}$ \\
2 & 1.0 & 3.0 & -0.023 \\
3 & 2.2 & 3.9 & 0.0058 \\
4 & 2.2 & 3.8 & -0.001 \\
& & & -0.0021 \\
\hline
\end{tabular}

compression amount is of more interest than the initial collapse strength.

Olurin's (2000) values for $\sigma_{\text {crush }}$ for aluminum foam range from 1.4 to $2.8 \mathrm{MPa}$. Data for the bulk material properties of Alporas, the trade name for the aluminum foam used in Olurin's studies, could not be found, but the ultimate strength of a few randomly selected brittle aluminum alloys on www. matweb.com is in the $500 \mathrm{MPa}$ range. The ultimate brittle failure strength of water ice, in comparison, is $\sim 10 \mathrm{MPa}$ (Gold, 1977). The ratio of ultimate failure strength of bulk material to crush strength of associated foam is two orders of magnitude for aluminum/aluminum foam and four orders of magnitude for ice/snow. Although a direct comparison cannot be made because the exact material properties of bulk Alporas are unknown, it seems reasonable that the ratio of snow strength to ice strength be lower than the ratio of metal foam strength to bulk metal strength, because snow is formed from ice crystals sitting in contact, with perhaps some, but certainly no guaranteed, sintered bonds between individual crystals. Alporas foam, in contrast, is formed by injecting air bubbles into a molten metal matrix, then cooling it (Miyoshi and others, 2000). This is counter to ice, and, in theory, the metal matrix could have the same crystal structure as the bulk metal. It is also of interest to note that for the snow density range studied here, the ratio of snow tensile strength to that of ice can be very small as summarized by Petrovic (2003).

Despite the higher test-to-test repeatability and fundamental nature of the plateau strength, it still exhibits considerable scatter, This is to be expected from a natural, non-engineered material. Smaller scatter has been obtained for artificial snows (Shoop and Alger, 1998). Differences in mechanical performance among natural, sorted and artificial snows are discussed by Yong and Fukue (1977). The literature on synthetic foams also exhibits very little scatter in engineered materials (Andrews and others, 2001; Ramamurty and Kumaran, 2004; Lu and others, 2008; Flores-Johnson and Li, 2010).

\subsection{Energy absorption}

Coarse-grained snow exhibited decreasing energy absorption ability with increasing indenter diameter. This decrease was not linear, flattening out to suggest energy absorption independence of size at larger diameters. Fine-grained snow showed much greater scatter, suggesting there was greater variability of absorption capabilities with different samples than for coarse-grained snow. This could be because snow collection of fine-grained samples took place over many months (November-March of each boreal season), with much more potential for varying snow conditions, while collection of coarse-grained samples only occurred in March, allowing less variation. 


\section{CONCLUSIONS}

Mechanical indentation testing of snow has provided results consistent both from test to test and from one snow season to another.

Strength tests on snow indicate a power law decrease of first peak failure strength with increasing indenter diameter. The average value of the power law exponent was 0.83 for fine-grained snow and 0.85 for coarse-grained snow. The average value over both snow types was 0.84 with a COV of 0.15 .

The average plateau strength decreased with increasing diameter, and the data presented here ranged from 3100 to $7500 \mathrm{~Pa}$. Following the example of Olurin and others (2000), plateau strength values were used to calculate the crush strength of the snow, which ranged from 3 to $13 \mathrm{kPa}$, and the tearing strength, which was determined as being negligible.

The average energy absorption densities were constant with respect to indenter size for fine-grained snow, and decreased with increasing indenter size for coarse-grained snow but may become independent of indenter size at sufficiently large diameter. We found average energy absorption density was $3.4 \times 10^{-7}$ for fine-grained snow and $4.1 \times 10^{-7}$ for coarse-grained snow.

We have attempted to extract properties of pure, dry, undisturbed snow. In nature, snow is subject to other forces and factors (e.g. wind, impurities, temperature fluctuations and humidity). These factors need to be taken into account as they affect snow's intrinsic strength and its surface properties.

For engineering applications additionally, if the interfacing material of interest (e.g. tire rubber) is pliant, the properties of the interfacing material need to be taken into account along with the properties of the snow.

It must also be noted that the size effects discussed here have only been tested on the scales reported, and should not be extrapolated beyond the end points of the data presented here.

The key conclusions from this study are:

First peak failure strength for snow exhibits a power law decrease with increasing indenter diameter.

The power law exponent for the relationship between first peak failure strength and indenter diameter is highly repeatable.

Plateau strength for snow decreases with increasing indenter diameter, and is a more fundamental characterization of snow than first peak strength.

Material properties concerning crushing strength can be calculated from the plateau strength. Tearing strength is negligible.

Energy absorption density decreases with increasing indenter diameter in small size ranges, and is independent of indenter diameter above a certain minimum size.

\section{ACKNOWLEDGEMENTS}

We gratefully acknowledge support for this work by the US Army TACOM Life Cycle Command under contract No. W56HZV-08-C-0236, through a subcontract with Mississippi State University. This work was performed in part for the Simulation Based Reliability and Safety (SimBRS) research program. Any opinions, findings and conclusions or recommendations expressed in this material are those of the authors and do not necessarily reflect the views of the US Army TACOM.

Disclaimer: Reference herein to any specific commercial company, product, process, or service by trade name, trademark, manufacturer, or otherwise, does not necessarily constitute or imply its endorsement, recommendation, or favoring by the United States Government or the Department of the Army (DoA). The opinions of the authors expressed herein do not necessarily state or reflect those of the United States Government or the DoA, and shall not be used for advertising or product endorsement purposes.

\section{REFERENCES}

Andrews EW, Gioux G, Onck P and Gibson LJ (2001) Size effects in ductile cellular solids. Part II: experimental results. Int. J. Mech. Sci., 43(3), 701-713 (doi: 10.1016/S0020-7403(00)00043-6)

Brown RL (1994) Changes in microstructural parameters of snow during deformation. Montana State University, Bozeman, MT

Dowd T and Brown RL (1986) A new instrument for determining strength profiles in snow cover. J. Glaciol., 32(111), 299-301

Edens MQ and Brown RL (1991) Changes in microstructure of snow under large deformations. J. Glaciol., 37(126), 193-202

Fierz C and 8 others. (2009) The international classification for seasonal snow on the ground. UNESCO-International Hydrological Programme, Paris (IHP-VII Technical Documents in Hydrology 83)

Floyer JA and Jamieson JB (2010) Rate-effect experiments on roundtipped penetrometer insertion into uniform snow. J. Glaciol., 56(198), 664-672 (doi: 10.3189/002214310793146322)

Fores-Johnson EA and Li QM (2010) Indentation into polymeric foams. Int. J. Solids Struct., 47(16), 1987-1995 (doi: 10.1016/ j.ijsolstr.2010.03.025)

Gibson LJ and Ashby MF (1999) Cellular solids: structure and properties, 2nd edn. Cambridge University Press, Cambridge

Gold LW (1977) Engineering properties of fresh-water ice. J. Glaciol., 19(81), 197-212

Gubler HU (1975) On the Rammsonde hardness equation. IAHS Publ. 114 (Symposium at Grindelwald 1974 - Snow Mechanics), 110-121

Jellinek HHG (1959) Compressive strength properties of snow. J. Glaciol., 3(25), 345-354

Johnson JB and Hopkins MA (2005) Identifying microstructural deformation mechanisms in snow using discreteelement modeling. J. Glaciol., 51(173), 432-442 (doi: 10.3189/ 172756505781829188)

Johnson JB and Schneebeli M (1999) Characterizing the microstructural and micromechanical properties of snow. Cold Reg. Sci. Technol., 30(1-3), 91-100

Kinosita S (1967) Compression of snow at constant speed. In Oura $\mathrm{H}$ ed. Physics of snow and ice. Institute of Low Temperature Science, Hokkaido University, Sapporo, 911-927

Kirchner HOK, Michot G, Narita H and Suzuki T (2001) Snow as a foam of ice: plasticity, fracture and the brittle-to-ductile transition. Philos. Mag. A, 81(9), 2161-2181 (doi: 10.1080/ 01418610108217141)

Lee JH (2009) A new indentation model for snow. J. Terramech., 46(1), 1-13 (doi: 10.1016/j.jterra.2009.02.001)

Lee J (2011) An improved slip-based model for tire-snow interaction. SAE Int. J. Mater. Manuf., 4(1), 278-288 (doi: 10.4271/ 2011-01-0188)

Lee JH, Huang D, Marshall HP and Johnson JB (2009) Microscale direct simulation of snow penetration tests and inversion of signals. In Proceedings of the 11th European Regional Conference of the International Society for Terrain-Vehicle Systems, 5-8 October 2009, Bremen, Germany. International Society for Terrain-Vehicle Systems 
Lu G, Shen J, Hou W, Ruan D and Ong LS (2008) Dynamic indentation and penetration of aluminium foams. Int. J. Mech. Sci., 50(5), 932-943 (doi: 10.1016/j.ijmecsci.2007.09.006)

Marshall HP and Johnson JB (2009) Accurate inversion of highresolution snow penetrometer signals for microstructural and micromechanical properties. J. Geophys. Res., 114(F4), F04016 (doi: 10.1029/2009JF001269)

McClung DM (1981) Failure characteristics of alpine snow in slow deformation. In Selvadurai APS ed. Mechanics of Structured Media: Proceedings of the International Symposium on the Mechanical Behaviour of Structured Media, 18-21 May 1981, Ottawa, Canada. Elsevier Scientific, Amsterdam, 409-418

Mellor M (1975) A review of basic snow mechanics. IAHS Publ. 114 (Symposium at Grindelwald 1974 - Snow Mechanics), 251-291

Miyoshi T, Itoh M, Akiyama S and Kitahara A (2000) ALPORAS aluminium foam: production process, properties, and applications. Adv. Eng. Mater., 2(4), 179-183 (doi: 10.1002/(SICI)15272648(200004)2:4<179::AID-ADEM179>3.0.CO;2-G)

Muro T and O'Brien J (2004) Terramechanics: land locomotion mechanics. A. A. Balkema, Lisse

Muro T and Yong RN (1980) Rectangular plate loading test on snow - mobility of tracked oversnow vehicle. Seppyo, J. Jpn. Soc. Snow Ice, 42(1), 17-24 [in Japanese with English summary]

Nemat-Nasser S and Hori M (1999) Micromechanics: overall properties of heterogeneous materials, 2nd edn. Elsevier Science, Amsterdam

Olurin OB, Fleck NA and Ashby MF (2000) Indentation resistance of an aluminium foam. Scripta Mater., 43(11), 983-989 (doi: 10.1016/S1359-6462(00)00519-4)

Onck PR, Andrews EW and Gibson LJ (2001) Size effects in ductile cellular solids. Part I: modeling. Int. J. Mech. Sci., 43(3), 681-699 (doi: 10.1016/S0020-7403(00)00042-4)

Petrovic JJ (2003) Review: mechanical properties of ice and snow. J. Mater. Sci., 38(1), 1-6 (doi: 10.1023/A:1021134128038)
Ramamurty U and Kumaran MC (2004) Mechanical property extraction through conical indentation of a closed-cell aluminum foam. Acta Mater., 52(1), 181-189 (doi: 10.1016/ j.actamat.2003.09.004)

Schneebeli M, Pielmeier C and Johnson JB (1999) Measuring snow microstructure and hardness using a high resolution penetrometer. Cold Reg. Sci. Technol., 30(1-3), 101-114 (doi: 10.1016/S0165-232X(99)00030-0)

Schulson EM (1999) The structure and mechanical behavior of ice. JOM, 51(2), 21-27 (doi: 10.1007/s11837-999-0206-4)

Seligman G (1936) Snow structure and ski fields: being an account of snow and ice forms met with in nature, and a study on avalanches and snowcraft. Macmillan, London

Shoop S and Alger R (1998) Snow deformation beneath a vertically loaded plate: formation of pressure bulb with limited lateral displacement. In Newcomb DE ed. Cold Regions Impact on Civil Works: Proceedings of the 9th International Conference on Cold Regions Engineering, 27-30 September 1998, Duluth, Minnesota. American Society of Civil Engineers, Reston, VA, 143-150

Wong JY (2001) Theory of ground vehicles, 3rd edn. Wiley, New York

Yong RN and Fukue M (1977) Performance of snow in confined compression. J. Terramech., 14(2), 59-82 (doi: 10.1016/00224898(77)90002-7)

Yosida Z and 6 others (1956) Physical studies on deposited snow. Part II: mechanical properties. Contrib. Inst. Low Temp. Sci., Ser. A, 9(1), 1-81

Yuan H (2007) Stochastic reconstruction of snow microstructure from $x$-ray microtomography images. University of Alaska Fairbanks, Fairbanks, AK

Yuan H, Lee JH and Guilkey JE (2010) Stochastic reconstruction of the microstructure of equilibrium form snow and computation of effective elastic properties. J. Glaciol., 56(197), 405-414 (doi: 10.3189/002214310792447770) 